\title{
A Noncanonical Role for Plasminogen Activator Inhibitor Type 1 in Obesity-Induced Diabetes
}

Gina M. Coudriet, ${ }^{\star}$ John Stoops, ${ }^{\dagger}$ Anne V. Orr, ${ }^{\dagger}$ Bharat Bhushan, ${ }^{\dagger}$ Kelly Koral, ${ }^{\dagger}$ Sojin Lee,${ }^{\ddagger}$ Dana M. Previte, ${ }^{*}$ H. Henry Dong, George K. Michalopoulos, ${ }^{\dagger}$ Wendy M. Mars, ${ }^{\dagger}$ and Jon D. Piganelli*

From the Departments of Surgery* and Pediatrics, ${ }^{\ddagger}$ UPMC Children’s Hospital of Pittsburgh, and the Department of Pathology, ${ }^{\dagger}$ University of Pittsburgh School of Medicine, Pittsburgh, Pennsylvania

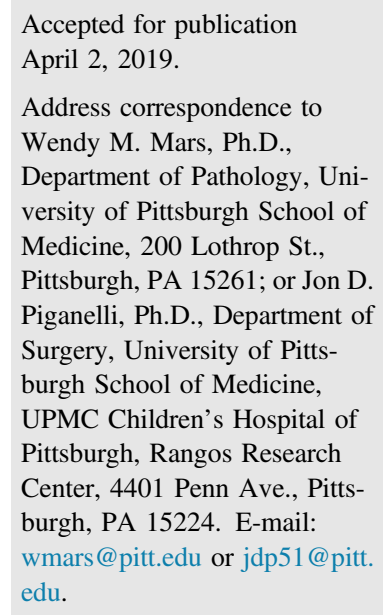

\begin{abstract}
Obesity is a major risk factor for type 2 diabetes because of chronic hepatic inflammation and resultant insulin resistance. Hepatocyte growth factor (HGF) is responsible for resetting hepatic homeostasis after injury following activation by urokinase-type plasminogen activator ( $\mathrm{U}-\mathrm{PA}$; encoded by the PLAU gene). Plasminogen activator inhibitor type-1 (PAI-1; encoded by the SERPINE1 gene), a u-PA inhibitor and antifibrinolytic agent, is often elevated in obesity and is linked to cardiovascular events. We hypothesized that, in addition to its role in preventing fibrinolysis, elevated PAI-1 inhibits HGF's activation by u-PA and the resultant anti-inflammatory and hepatoprotective properties. Wild-type and PAI-1 knockout (KO) mice on a high-fat diet both became significantly heavier than lean controls; however, the obese K0 mice demonstrated improved glucose metabolism compared with wild-type mice. Obese $\mathrm{KO}$ mice also exhibited an increase in conversion of latent single-chain HGF to active two-chain $\mathrm{HGF}$, coinciding with an increase in the phosphorylation of the HGF receptor (HGFR or MET, encoded by the MET gene), as well as dampened inflammation. These results strongly suggest that, in addition to its other functions, PAI-mediated inhibition of HGF activation prohibits the resolution of inflammation in the context of obesity-induced type 2 diabetes. (Am J Pathol 2019, 189: 1413-1422; https://doi.org/10.1016/j.ajpath.2019.04.004)
\end{abstract}

Type 2 diabetes (T2D) is characterized by an increase of hepatic glucose, impaired insulin secretion, and obesity. It is thought that in the development of T2D, overnutrition because of increased caloric intake leads to a dysfunction in metabolic homeostasis from the overwhelming presence of adipose tissue. ${ }^{1}$ This dysregulation is characterized by elevated proinflammatory cytokine production that comes from macrophages in the liver and adipose tissue, ultimately leading to insulin resistance. ${ }^{1-6}$

Cytokines secreted by the liver reflect the presence and intensity of inflammation and are part of how the liver attempts to maintain systemic homeostasis during stress, infection, and/or injury. ${ }^{7,8}$ On the other hand, proper homeostasis of the liver itself is regulated by a protein known as hepatocyte growth factor (HGF), a mitogen for liver repair and maintenance that is transcribed in response to the proinflammatory cytokine IL-6. ${ }^{9}$ Among its other physiological functions, HGF plays a key role in resetting the hepatic homeostatic threshold after injury. ${ }^{10,11}$ In liver, this is achieved after cleavage of latent, single-chain HGF (scHGF) to its active two-chain form (tcHGF) by the urokinase-type plasminogen activator (u-PA). ${ }^{12,13}$ u-PA's activity is regulated by plasminogen activator inhibitor type1 (PAI-1), an acute phase protein and antifibrinolytic agent, which is consistently up-regulated in obesity and linked to elevated cardiovascular anomalies in obese patients. ${ }^{14-16}$ Another critically important outcome of hepatic PAI-1 is

\footnotetext{
Supported by the American Heart Association predoctoral grant 0615393 U (G.M.C.), the UPMC Children's Hospital of Pittsburgh Research Advisory Committee predoctoral award (G.M.C.), the Cleveland Foundation (G.K.M.), the Menten Endowment of the University of Pittsburgh (G.K.M.), the Juvenile Diabetes Research Foundation Ltd. grant 7601 (J.D.P.), and the American Diabetes Association Career Development Award 7.07 (J.D.P.).

W.M.M. and J.D.P. contributed equally to this work as senior authors. Disclosures: None declared.
} 
the inhibition of u-PA that subsequently prevents activation of HGF. ${ }^{12,17,18}$ As HGF must be active to signal through its receptor, MET, ${ }^{12,19,20}$ and as evidence suggests that active tcHGF can have a palliative role in diabetes, ${ }^{21,22}$ possibly because of its role in regulating the insulin receptor, ${ }^{23}$ it is reasonable to hypothesize that in addition to its role in preventing fibrinolysis, an obesity-induced increase in PAI1 protein could lead to the accumulation of nonactive scHGF, thereby exacerbating the disease process.

Although active tcHGF can induce IL- 6 production in hepatocytes,${ }^{24}$ it suppresses immune cell IL- 6 production in a glycogen synthase kinase-3 $\beta$-dependent manner. ${ }^{25}$ Therefore, in the earliest developmental stages that can lead to nutrition-induced T2D, tcHGF is a likely candidate for inducing IL-6 production in hepatocytes while simultaneously suppressing the early, macrophage-mediated production of cytokines. On the other hand, over time, as prolonged, obesity-induced stress generates PAI-1 production that coincides with the development of $\mathrm{T} 2 \mathrm{D}$, the expectation would be that PAI-1-mediated inactivation of HGF would no longer be able to induce hepatocellular IL-6 or suppress its expression from immune cells.

Herein, we characterized the PAI-1 knockout (KO) mouse to definitively show the role PAI-1 plays in HGF activation and subsequent inflammatory-mediated induction of diabetes. Wild-type (WT) and KO mice were either fed normal chow or a high-fat diet (HFD) for a period of 20 weeks, and parameters related to the development of T2D were assessed. The results demonstrate that in WT mice, overnutrition leads to weight gain, glucose intolerance, and insulin resistance, as well as elevated PAI-1 levels. The increase in PAI-1 corresponds with a decrease in the conversion of scHGF to tcHGF and subsequent reductions in MET phosphorylation; these events coincide with classic, unresolved chronic inflammation. When PAI-1 KO mice are fed the HFD, with the exception of weight gain, the phenotype is abrogated, including the deleterious effects of obesity-mediated inflammation. As active HGF is known to have a palliative role in $\mathrm{T} 2 \mathrm{D}$, these positive changes are attributed to unabated HGF activation when PAI-1 is absent.

\section{Materials and Methods}

\section{Mice}

For most experiments, 6- to 8-week-old male C57BL/6J (WT) and B6.129S2-Serpine $1<\mathrm{tm} 1 \mathrm{Mlg}>/ \mathrm{J}$ (PAI-1 KO) mice were purchased from The Jackson Laboratory (Bar Harbor, ME). Mice were fed either an HFD, consisting of $60 \% \mathrm{kcal}$ fat and $20 \% \mathrm{kcal}$ each protein and carbohydrate (D12492; Research Diets, New Brunswick, NJ), or standard chow. The animals were fed the diets for 20 weeks, and body weight was recorded weekly until termination of the experiment. For some experiments, animals were fed an accelerated fast food diet for 20 weeks that maintains a higher than normal fat content but that also includes a higher than normal carbohydrate component. ${ }^{26}$ Animals with exon 16 of MET specifically deleted from their hepatocytes were generated by crossing MET $^{f / f}$ mice (a gift from Snorri Thorgeirsson, currently available at The Jackson Laboratories as 016974, Mettm1Sst) with animals expressing Cre recombinase under an $\alpha$-fetoprotein enhancer-driven albumin promoter. ${ }^{27}$ All animals were housed under specific pathogen-free conditions in the animal facility at the University of Pittsburgh (Pittsburgh, PA). This study was performed in strict accordance with the recommendations in the Guide for the Care and Use of Laboratory Animals of the $\mathrm{NIH}{ }^{28}$ The protocol was approved by the Institutional Animal Care and Use Committee of the University of Pittsburgh (assurance number A3187-01).

\section{I.P. Glucose Tolerance Test}

A $1 \mathrm{~g} / \mathrm{kg}$ dose of glucose was administered intraperitoneally to fasted mice (12 hours) at 20 weeks after normal or HFD feeding. Blood glucose readings were taken at 0 (before glucose injection), 30, 60, 90, and 120 minutes after glucose injection and measured using a Bayer Breeze2 glucometer (Bayer AG, Leverkusen, Germany).

\section{HOMA-IR Data}

The homeostatic model assessment-estimated insulin resistance (HOMA-IR) index was calculated as a measure of insulin sensitivity, as follows:

HOMA-IR $=$ [fasting glucose $(\mathrm{mg} / \mathrm{dL}) \times$ fasting insulin $(\mathrm{U} / \mathrm{mL})] \div 405 .{ }^{29}$

\section{Glucose-Stimulated Insulin Secretion}

A $2 \mathrm{~g} / \mathrm{kg}$ dose of glucose was injected intraperitoneally after overnight fasting (12 hours). Blood glucose was measured immediately before injection and 15 minutes after injection using a Bayer Breeze2 glucometer.

\section{Serum PAI-1 Measurement}

PAI-1 levels were measured in the serum of WT and PAI-1 KO animals fed an HFD or standard chow at 2.5, 7.5, 11, and 20 weeks of feeding by a Milliplex Mouse Serum Adipokine Panel (Millipore, Billerica, MA).

\section{Quantitative Real-Time RT-PCR}

Quantitative real-time RT-PCR was performed, as previously described. ${ }^{30}$ The primer sequences for the RNAs encoding murine ribosomal protein L15 and PAI-1 are as follows: Rplo, 5'-GGCGACCTGGAAGTCCAACT-3' (forward) and 5'CCATCAGCACCACAGCCTTC-3' (reverse); and Serpine1, 5'-GATCAGTACTGCGGATGCCA-3' (forward) and 5'CCCCTTGGCCAGTAAGTCAC-3' (reverse). 

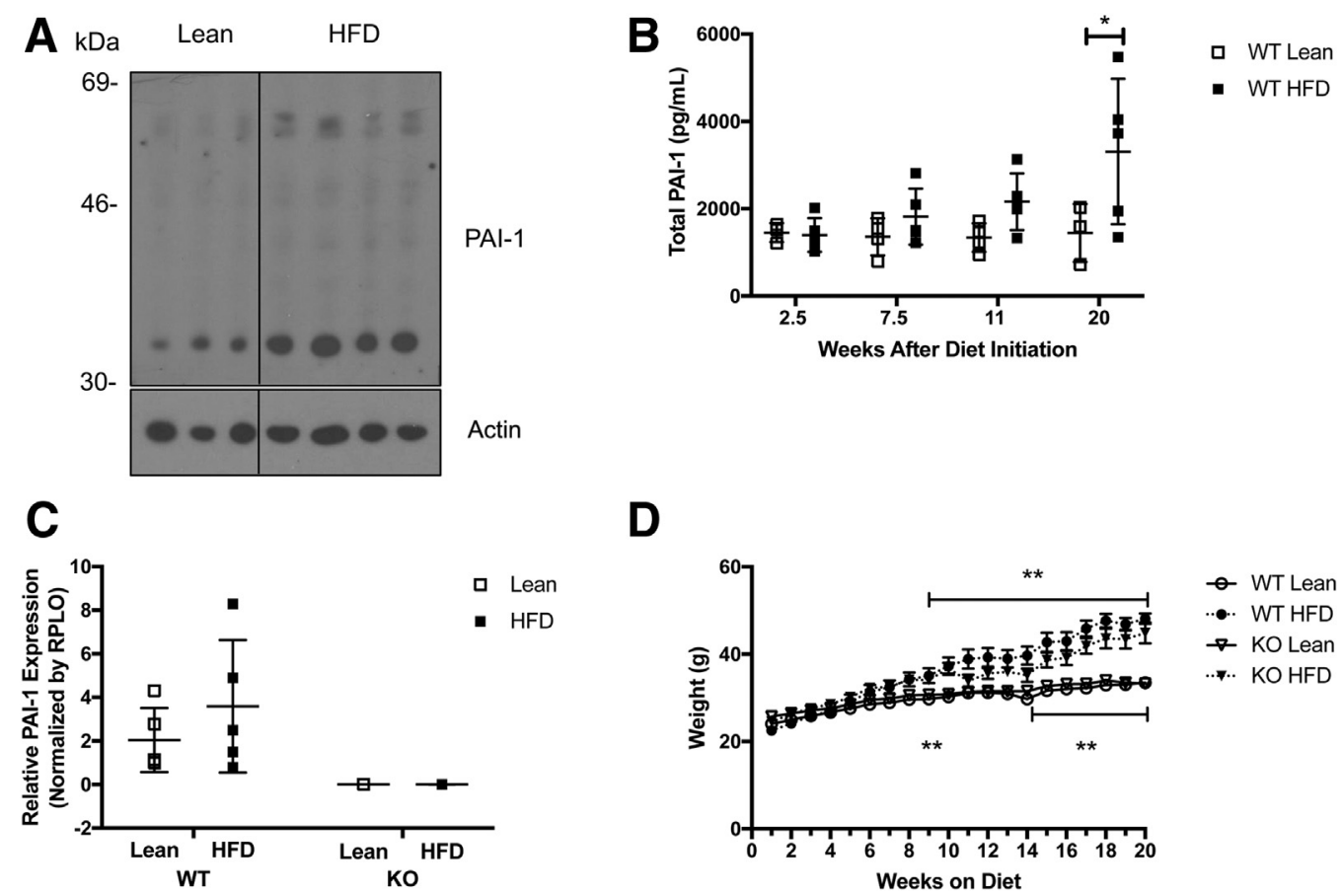

Figure 1 Changes in plasminogen activator inhibitor type-1 (PAI-1) levels with developing obesity. A: PAI-1 was analyzed by Western blot analysis in livers from C57BL6/J wild-type (WT) animals fed either standard chow (lean) or a diet of $60 \% \mathrm{kcal}$ of fat and $20 \% \mathrm{kcal}$ each protein and carbohydrate [high-fat diet (HFD)] at 12 weeks after the start of feeding. Blots were then stripped and reprobed with actin as a loading control. Each lane is from a different animal. B: Serum PAI-1 levels were measured in WT animals after 2.5, 7.5, 11, and 20 weeks of feeding the animals either a lean diet or an HFD. Unpaired $t$ tests were performed. C: Hepatic PAI-1 gene expression was measured by quantitative real-time RT-PCR after 20 weeks in WT and PAI-1 knockout (K0) mice fed either a lean diet or an HFD. One-way analysis of variance with a Tukey posttest was performed. D: Weight gain was monitored weekly in WT and PAI-1 KO mice fed either a lean diet or an HFD for 20 weeks. Two-way analysis of variance with a Bonferroni posttest was performed. Data are expressed as means \pm SEM (B-D). $n=5$ mice per group (D). ${ }^{*}<0.05$, $* * P<0.01$.

\section{Tissue Lysate Preparation and Western Blot Analysis}

Protein lysates from snap-frozen tissues were prepared and probed, as previously described, ${ }^{24}$ using a detergent-free lysis buffer $(10 \mathrm{mmol} / \mathrm{L}$ Tris-HCl, $\mathrm{pH} 7.5)$ with standard inhibitors. Amiloride and aprotinin were also added to the lysis buffer as they specifically inhibit u-PA and plasminogen activities, respectively. Once homogenized, the samples were centrifuged at $40,000 \times g$ for 30 minutes at $4^{\circ} \mathrm{C}$. The supernatants were saved, and the pellets were resuspended by sonication in $1 \%$ SDS-Tris buffer with inhibitors. Supernatants were enriched for cytosolic proteins; pellets represented a nuclear-, matrix-, and membrane-enriched fraction. The bicinchoninic acid protein assay (Thermo Fisher Scientific, Rockford, IL) was used to determine protein concentrations. Protein lysates were separated onto 10\% SDS-PAGE gels. After transfer, membranes were stained with Ponceau S. Western blot analyses were performed with antibodies to PAI-1 (sc-8979; Santa Cruz Biotechnology, Dallas, TX), HGF (AF2207; R\&D Systems, Minneapolis, MN), phosphorylated MET (Y1349; number 3121; Cell Signaling Technology, Danvers, MA), and total MET (number 3127; Cell Signaling Technology) in 5\% fish gelatin in Tris-buffered saline with $0.1 \%$ Tween. Secondary antibodies, from Jackson ImmunoResearch (West Grove, PA), were used in $1 \%$ fish gelatin in Tris-buffered saline with $0.1 \%$ Tween. Chemiluminescence was detected using SuperSignal West Pico Chemiluminescent Substrate (Thermo Scientific, Rockford, IL). The blots were visualized using BioBlot BXR (Laboratory Product Services, Rochester, NY). Numbers obtained from ImageJ version 1.50i (NIH, Bethesda, MD; https://imagej.nih.gov) analyses were analyzed using Prism software version $7.0 \mathrm{~d}$ (GraphPad, San Diego, CA).

\section{Enzyme-Linked Immunosorbent Assay}

Hepatic IL-6 and tumor necrosis factor- $\alpha$ protein concentrations were measured by enzyme-linked immunosorbent assay (Abcam, Cambridge, MA), as previously described. ${ }^{29}$ Briefly, cytokine concentration was determined from liver lysates, and data are displayed as picograms of cytokine per milligrams of liver tissue.

\section{Histology}

Liver tissue harvested from WT and PAI-1 KO mice after 20 weeks of feeding was fixed in 10\% formalin and embedded in paraffin. Sections were stained with an antibody specific for IL-6 (Abcam) for immunohistochemistry. Antigen retrieval was performed using a citrate buffer, $\mathrm{pH}$ 6.0, for IL-6 staining and microwaving. Staining was 

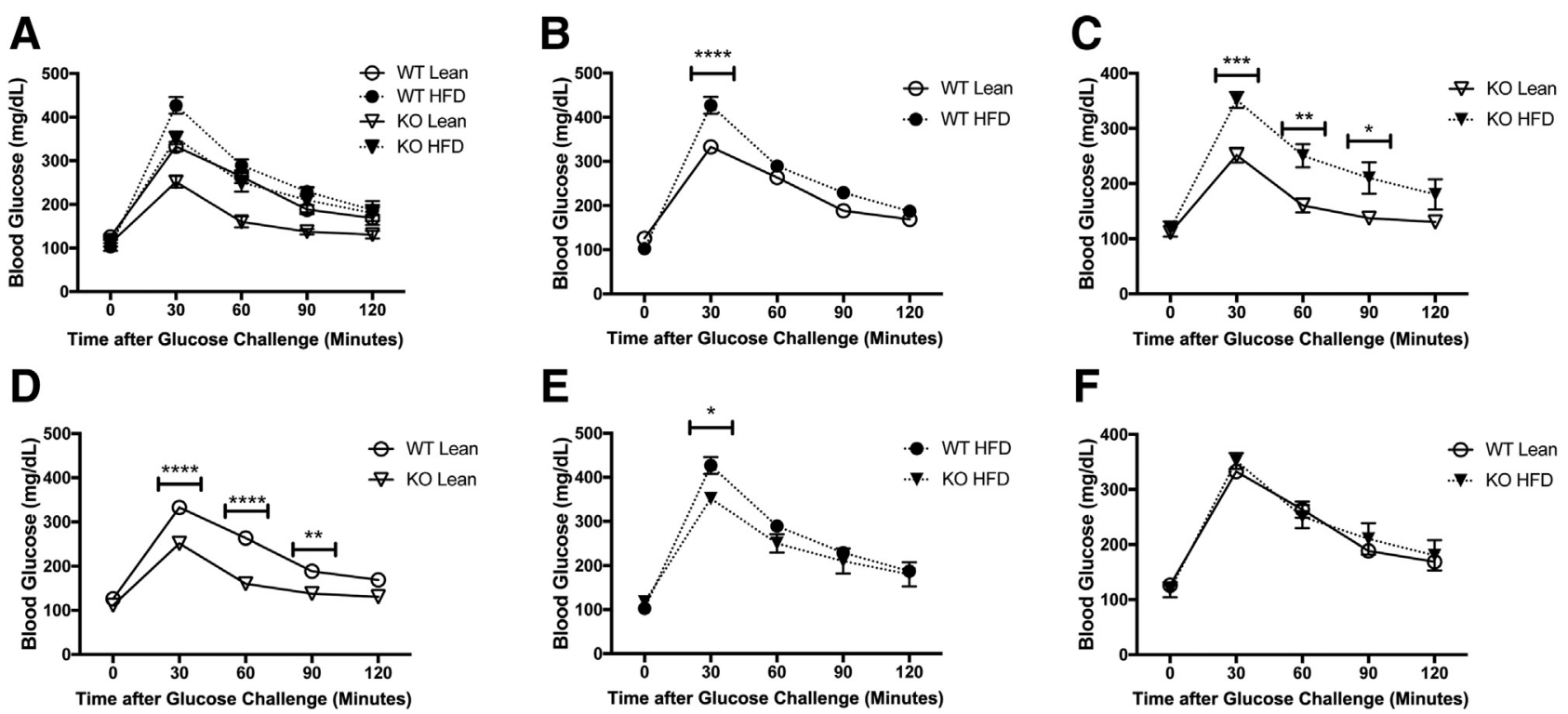

Figure 2 Effects on glucose metabolism as a result of plasminogen activator inhibitor type-1 deficiency. A-F: After overnight fasting, i.p. glucose tolerance tests were given to mice in all cohorts at 20 weeks of feeding. Blood glucose levels were recorded after a $1 \mathrm{~g} / \mathrm{kg}$ dose of glucose intraperitoneally over 120 minutes. Groups from A were separated to show clarity of statistical differences in B through F. Wild-type (WT) mice fed standard chow, open circles; WT mice fed a high-fat diet (HFD), closed circles; knockout (KO) mice fed lean chow, open triangles; and K0 mice fed an HFD chow, closed triangles. Two-way analysis of variance with a Bonferroni posttest was performed. Data are expressed as means \pm SEM. $n=5$ mice per group $(\mathbf{A}-\mathbf{F}) .{ }^{*} P<0.05, * * P<0.01$, $* * * P<0.001$, and $* * * * P<0.0001$.

visualized using a chromogenic substrate. Scoring for hepatocellular and immune cell IL-6 was performed using random images $(n=3$ per sample at $\times 400$ magnification) taken by one investigator (G.M.C.) and analyzed by a second investigator (K.K.) who was blinded to what the various samples were. Hepatocellular IL-6 was graded on an arbitrary scale of 1 to 5 , with 5 representing the highest overall staining level. For immune cells, the total number of positive cells in each image were counted.

\section{Statistical Analysis}

Prior work from our laboratory has demonstrated that group sizes of five or greater are sufficient for generating statistically meaningful results. All experiments were performed in at least triplicate. The differences between mean values were assessed by $t$-test or analysis of variance, with $P \leq 0.05$ considered significant. Significance was calculated using Prism software version 7. Data are displayed as means \pm SEM. Densitometry and immunohistochemistry quantification was calculated using the ImageJ software.

\section{Results}

\section{High-Fat Diet Induces PAI-1 and Obesity}

PAI-1 is known to be elevated in obesity and T2D and is associated with cardiovascular complications. ${ }^{31-33}$ To test the hypothesis that PAI-1 negatively regulates HGF in
A

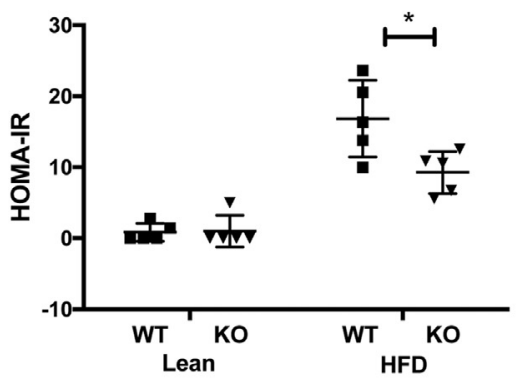

B

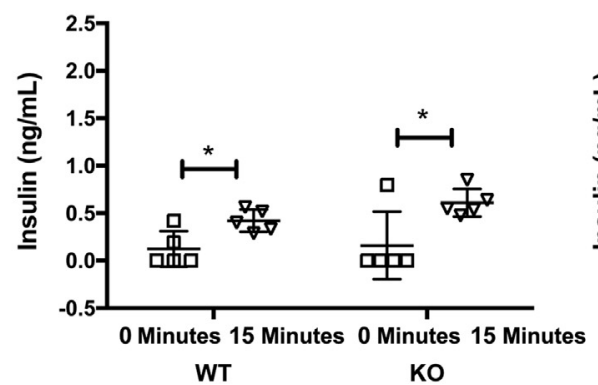

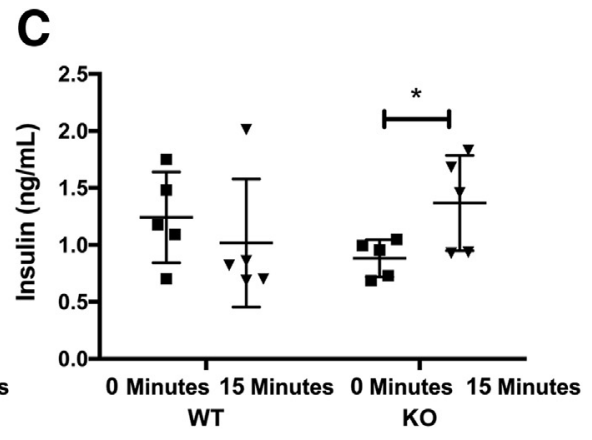

Figure 3 Effects of plasminogen activator inhibitor type-1 deficiency on insulin resistance. The homeostatic model assessment-estimated insulin resistance (HOMA-IR) index was calculated and glucose-stimulated insulin secretion (GSIS) was measured in mice from all cohorts at 20 weeks of feeding. A: HOMA-IR was calculated using fasting blood glucose and serum insulin levels ([fasting blood glucose $(\mathrm{mg} / \mathrm{dL}) \times$ fasting insulin $(\mu \mathrm{U} / \mathrm{mL})] / 405])$. B and C: In the fasted state, GSIS was measured at 0 and 15 minutes after a $2 \mathrm{~g} / \mathrm{kg}$ dose of glucose intraperitoneally in lean diet (B) or high-fat diet (HFD) fed (C) mice. Unpaired $t$ tests were performed. Data are expressed as means \pm SEM. $n=5$ mice per group $(\mathbf{A}-\mathbf{C}) .{ }^{*} P<0.05$. K0, knockout; WT, wild type. 

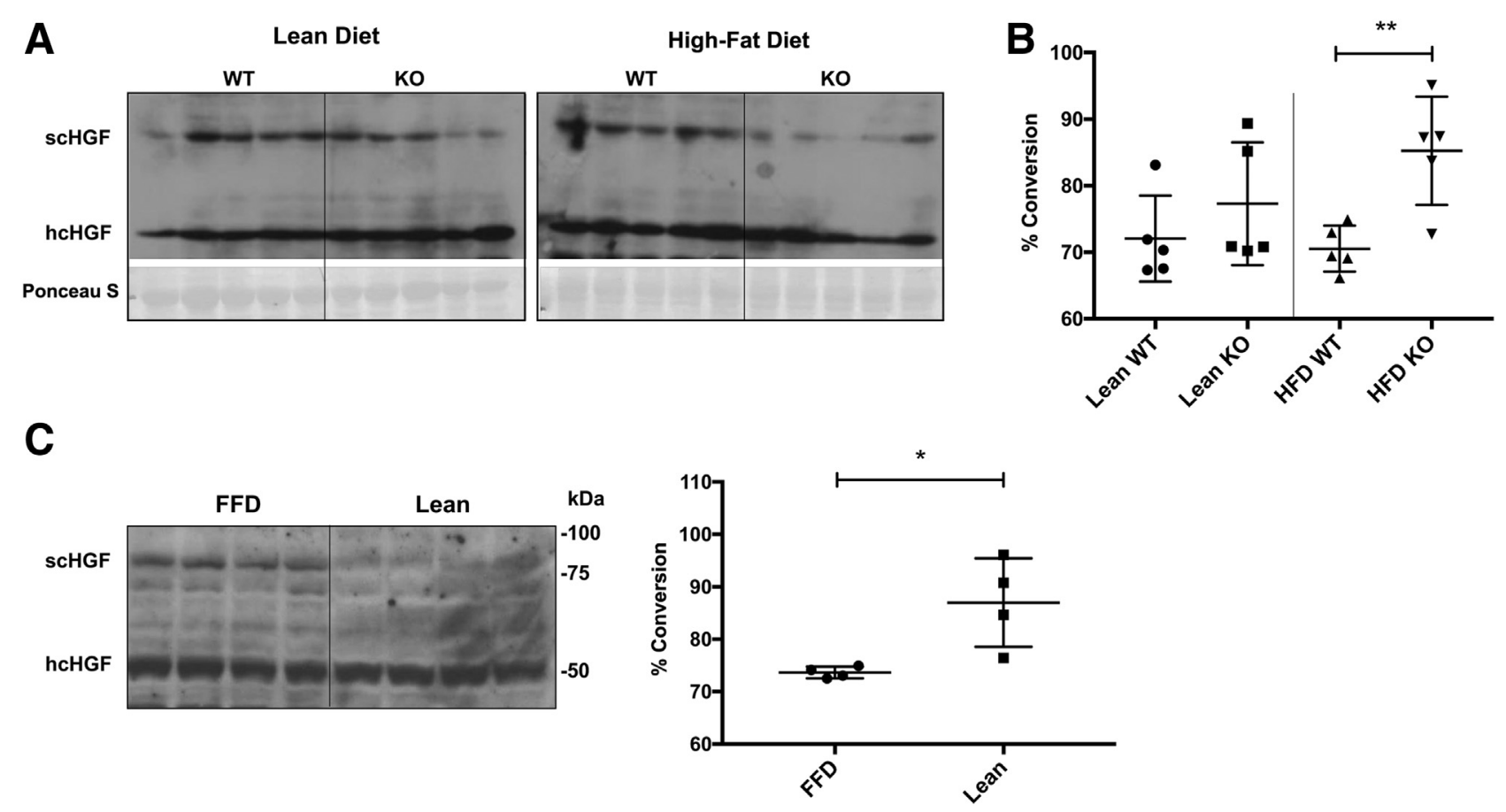

Figure 4 Plasminogen activator inhibitor type-1 (PAI-1) regulates conversion of latent hepatocyte growth factor (HGF) to its active two-chain form (tcHGF). Liver tissues were harvested from wild-type (WT) and PAI-1 knockout (K0) mice after 20 weeks of feeding. A: Western blot analysis for HGF was performed on cytoplasmic-enriched protein fractions from WT and PAI-1 KO mice after a high-fat diet (HFD) or standard chow feeding. B: After ensuring an overall evenness of protein loading using Ponceau S staining, the blots in A were quantified by densitometry. C: Western blot analysis for HGF was performed on membrane-enriched fractions from mice on an alternative, fast food diet (FFD, left panel) and results were quantified by densitometry (right panel). B and C: As the blots were probed with a polyclonal antibody that also detects the light chain (not depicted), the relative fraction of single-chain HGF (scHGF) converted to tcHGF was calculated using the formula: $100 \times[3 / 2$ heavy chain of tcHGF (hcHGF)/(3/2 hcHGF + scHGF)]. The assumption was that the hcHGF represents two-thirds of the tcHGF. Unpaired $t$ tests were performed. Each lane represents a separate animal. Data are expressed as means \pm SEM (B and C). $n$ $=5$ mice per group $(\mathbf{B}) .{ }^{*} P<0.05,{ }^{*} P<0.01$.

obesity-induced diabetes, the model was first verified by examining male WT mice fed an HFD for up to 20 weeks. Mice fed standard chow were also monitored for the duration of the study and considered lean controls. Although there are other models, the HFD-fed mouse model is a well-accepted model for studying obesityinduced insulin resistance. ${ }^{34}$ On immunoblotting, bands of approximately $55 \mathrm{kDa}$, corresponding to the reported size of full-length PAI-1, as well as secondary, lowermolecular-weight bands were elevated in the livers of animals after 12 weeks of feeding (Figure 1A). Furthermore, serum PAI-1 levels, as measured by a multiplex assay in WT mice, gradually became elevated and reached significance at 20 weeks of HFD feeding when compared with lean mice (Figure 1B). Although RNA levels did not reach significance, HFD-fed WT mice also exhibited a trend toward elevated gene expression for mRNAs encoding PAI-1 protein in the liver compared with lean mice, after 20 weeks of feeding (Figure 1C). RNAs from PAI-1 KO mice on standard and HFD served as negative controls.

Next, the effect of HFD was assessed on weight gain in the WT and KO mice. Figure 1D shows the body weights of all cohorts of WT and KO over 20 weeks of HFD or standard chow feeding. The overall body weight of HFDfed WT animals significantly increased compared with lean controls, beginning at 9 weeks after initiation of the diet. For the KO animals, although there was also a difference observed after 9 weeks on the diet, consistent differences in weight between lean and HFD were only noted after 14 weeks of feeding. There were no significant differences observed in body weight between the HFD or lean groups of either WT or KO mice throughout the study, although there was a trend toward a slightly lower weight gain for the KO mice on the HFD versus their WT counterparts.

\section{PAI-1 Alters Glucose Metabolism and Insulin Sensitivity}

To determine the effect of PAI-1 on glucose metabolism after HFD feeding, an i.p. glucose tolerance test was performed after 20 weeks of feeding (Figure 2). In both WT and KO animals, HFD negatively altered glucose metabolism when compared with their lean counterparts, starting at 30 minutes after glucose challenge (Figure 2, A-C). Interestingly, significant differences were observed when comparing lean WT with $\mathrm{KO}$ animals from 30 to 90 minutes 
A Normal Chow

WT KO
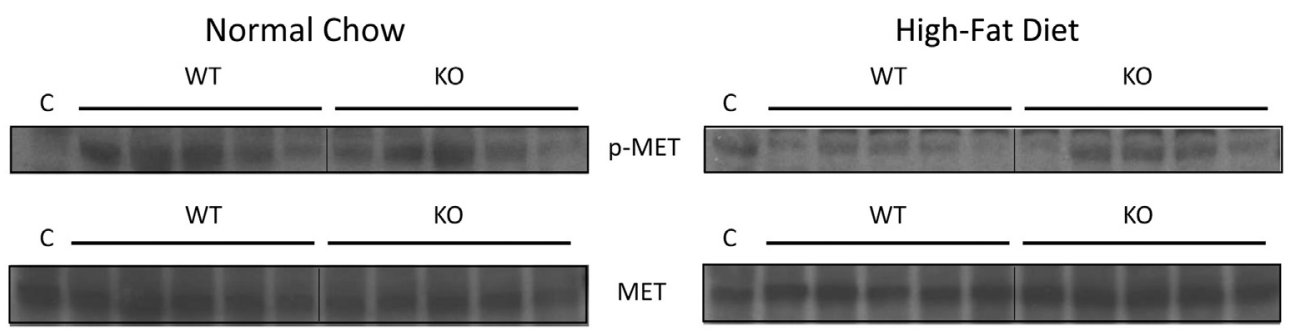
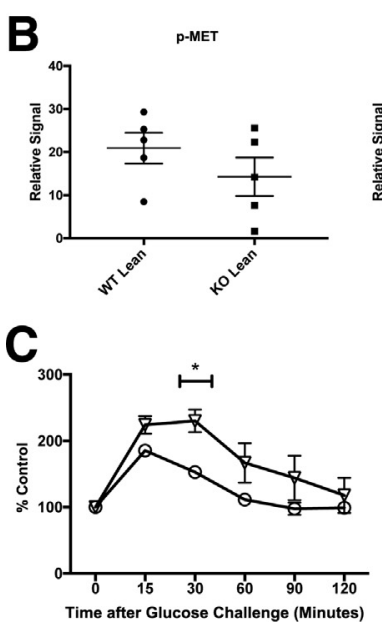
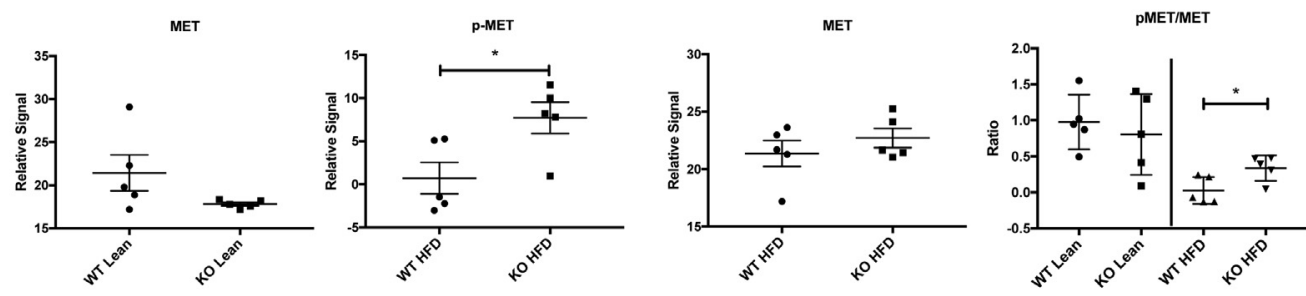

Figure 5 Plasminogen activator inhibitor type-1 regulates hepatocyte growth factor signaling through the hepatocellular MET receptor. A: Western blot analyses were performed on membrane-enriched liver lysates - WT Lean for phosphorylated MET (p-MET) and total MET protein on animals fed normal chow or a high-fat diet (HFD). $\forall$ cko Lean The controls (CS) for the Western diet using normal chow (lean) liver lysates were from an animal fed an HFD; and for the HFD blots, the $C$ was from an animal fed normal chow. B: Densitometric analyses of the blots shown in $\mathbf{A}$ was performed. Analyses of individual blots are shown along with the calculated ratio of $\mathrm{p}-\mathrm{MET} /$ MET (far right). C: Mice with a conditional deletion of the MET receptor from hepatocytes [conditional knockout (cKO)] and wild-type (WT) mice on a lean diet were subjected to a glucose tolerance test. Unpaired $t$ tests were performed. Data are expressed as means \pm SEM (B and C). $n=4$ (C, cKO mice); $n=3$ (C, WT mice on a lean diet). ${ }^{*} P<0.05$. after glucose challenge (Figure 2D), indicating that the absence of PAI-1 positively affects basal glucose metabolism. When comparing the WT with KO HFD-fed mice, the only significant difference was observed at 30 minutes after glucose challenge (Figure 2E). However, the most striking finding was that no significant differences in glucose tolerance were observed when comparing WT lean animals with KO HFD-fed animals (Figure 2F). This suggests that PAI-1 deficiency is able to combat obesityinduced glucose intolerance after 20 weeks of HFD feeding.

Concomitant with enhanced glucose tolerance, improved insulin resistance was observed in HFD-fed PAI-1 KO mice. HOMA-IR was used to estimate insulin sensitivity in all cohorts of mice. A higher HOMA-IR score equates to more severe insulin resistance. As expected, the lean WT and KO mice had a low HOMA-IR score that became elevated in WT mice after HFD feeding (Figure 3A). However, when KO mice were fed the HFD, their HOMAIR score was significantly decreased, compared with WT HFD animals. This correlates with results from an in vivo glucose-stimulated insulin secretion test. When fasted lean WT and PAI-1 KO mice were challenged with glucose, they both exhibited significant increases in glucosestimulated insulin secretion 15 minutes after glucose challenge, indicating that WT and $\mathrm{KO}$ mice on a normal diet are able to mount a normal insulin response (Figure 3B). In contrast, HFD feeding in WT mice thwarted insulin sensitivity, during which the mice remained insulin insensitive 15 minutes after glucose challenge (Figure 3C). However, in accordance with the HOMA-IR results, HFD- fed PAI-1 KO mice remained insulin sensitive, with a significant increase in insulin secretion 15 minutes after glucose challenge.

\section{PAI-1 Regulates Activation of HGF and Subsequent Signaling through MET}

HGF signaling through MET is known to ameliorate the effects of experimental stressors on pancreatic islets in animal models of diabetes ${ }^{21,22}$ and has been shown to alter insulin resistance, ${ }^{23}$ possibly in a macrophage-specific manner. ${ }^{35,36}$ In liver, u-PA is known to process latent, scHGF to active, $\operatorname{tcHGF}^{12,13}$ in a high-affinity, stoichiometric manner. ${ }^{37}$ As PAI-1 is a known inhibitor of u-PA, ${ }^{38}$ we hypothesized that excess hepatic PAI-1 might disrupt HGF activation in liver, leading to impaired signaling through MET. Western blot analyses of cytoplasm-enriched liver lysates from WT and KO mice on the lean diet show no significant difference in the conversion of scHGF to tcHGF. However, when mice were fed the HFD for 20 weeks and PAI-1 became elevated, there was a significant increase in the amount of tcHGF versus scHGF in the PAI-1 KO mice compared with WT mice, indicating increased conversion had taken place (Figure 4).

Although u-PA and PAI-1 are known to regulate HGF activation in liver, there are also several other known activators and inhibitors of HGF that can regulate activation, such as tissue plasminogen activator, ${ }^{13}$ HGF activator ${ }^{39}$ and its inhibitors, HAI- ${ }^{40}$ and HAI- $2,{ }^{41}$ matriptase, and hep$\sin ^{42}$ To determine whether the correlation between excess 

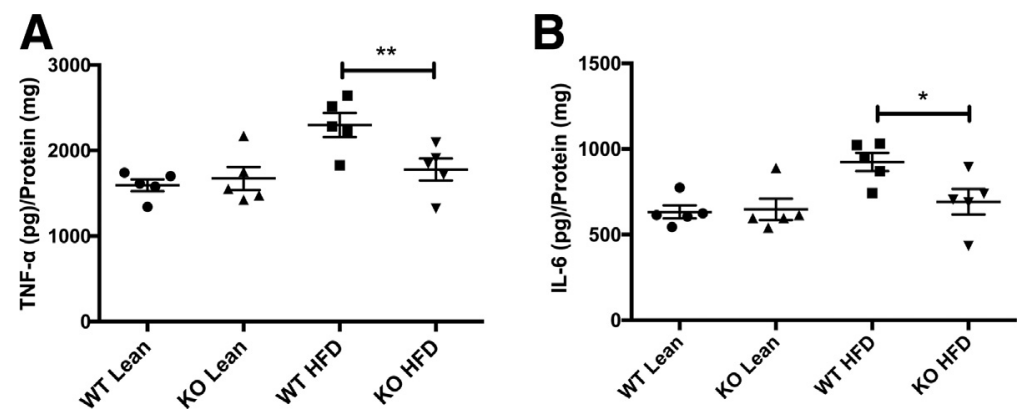
Figure 6 Absence of plasminogen activator inhibitor type-1 prevents high-fat diet (HFD)- mediated induction of cytokines. Enzyme-linked immunosorbent assays were performed on hepat- ic lysates for tumor necrosis factor (TNF) $-\alpha$ (A) and IL-6 (B), and results were analyzed by one- way analysis of variance with a Tukey posttest. Data are expressed as means \pm SEM. ${ }^{*} P<0.05$, ${ }^{* *} P<0.01$. K0, knockout; WT, wild type.

PAI-1 and impaired HGF cleavage observed in the WT mice fed an HFD (Figure 1) was unique to this model or a more general phenomenon, an alternative HFD known as the Western or fast food diet, which has a lower fat content but a higher carbohydrate load, was used. First, Western blot analyses were performed to confirm that PAI-1 was similarly elevated in animals on the fast food diet (data not shown). Next, Western blot analyses were performed for HGF, this time using membrane-enriched samples to specifically assess the activation status of HGF on the cell surface. Although efficient HGF processing occurs in membranes from WT animals fed a lean diet, processing in animals fed the fast food diet is impaired (Figure 4C).
Next, it was ascertained whether the increase in active HGF observed in the KO animals on an HFD was able to affect signaling through MET and subsequent glucose sensitivity; Western blot and subsequent densitometric analyses for phosphorylated MET Y1349 and total MET were performed on membrane-enriched fractions from liver lysates (Figure 5, A and B). Although total MET levels were not significantly different, WT mice fed the HFD had a significant decrease in the phosphorylation status of MET (phosphorylated MET Y1349), relative to HFD-fed PAI-1 KO mice. This change was reflected as a decrease in the phosphorylated MET/MET ratio. To determine whether it was loss of HGF signaling on
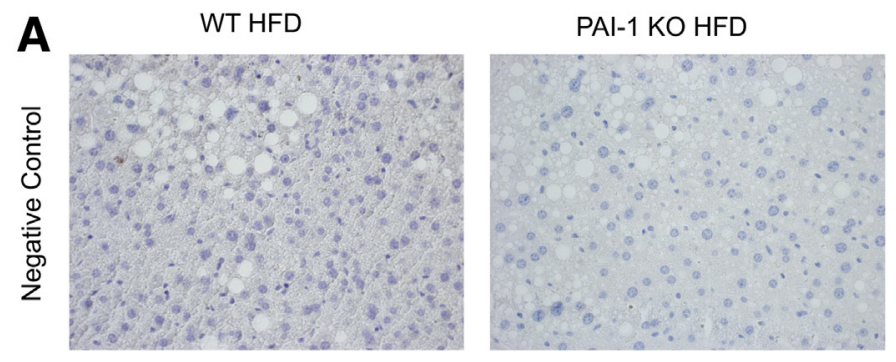

B
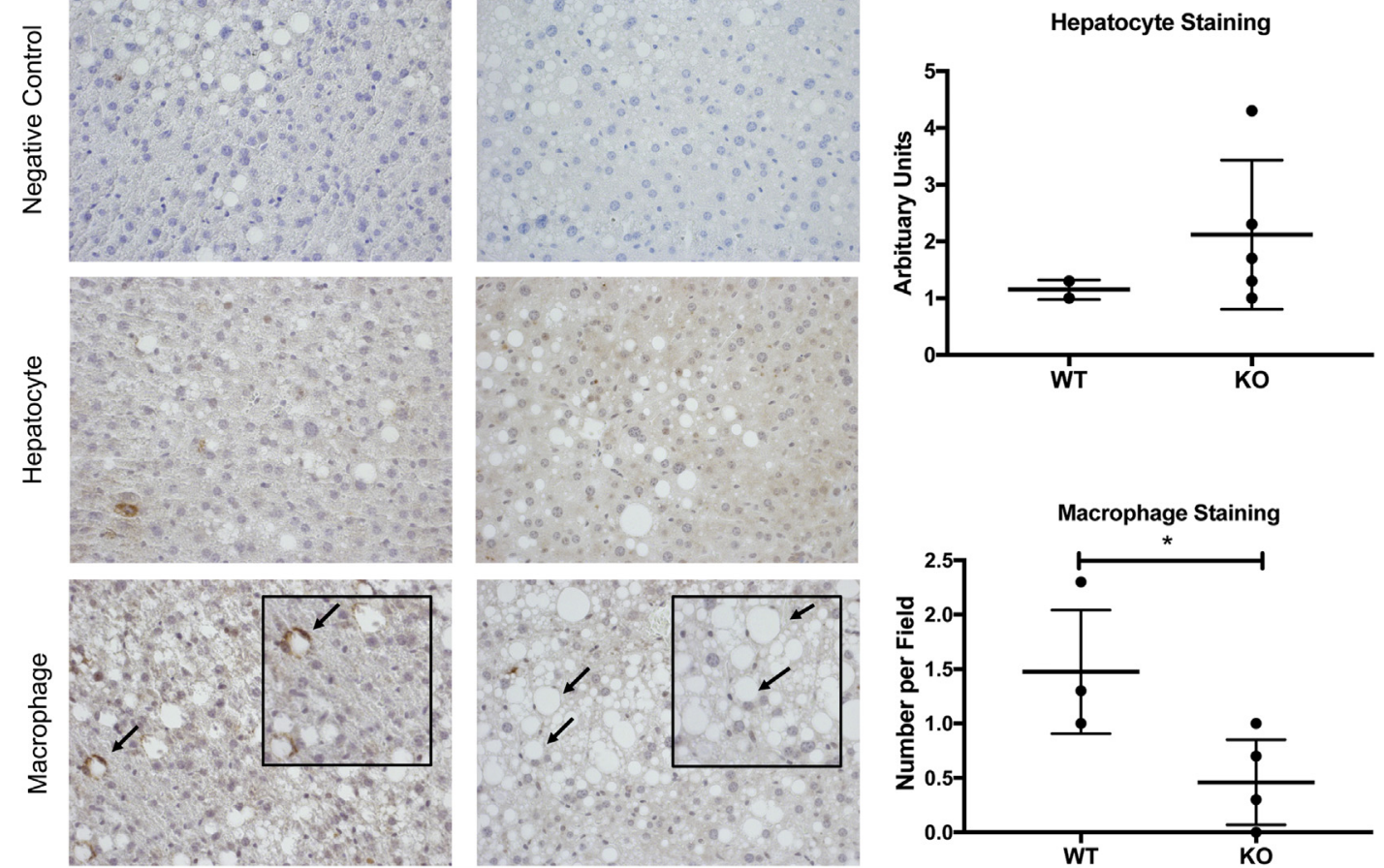

Figure 7 Plasminogen activator inhibitor type-1 (PAI-1) deficiency contributes to differential expression of IL-6 by hepatocytes and macrophages. After 20 weeks of feeding, liver tissues were harvested and paraffin sections were stained with an IL-6-specific antibody. Slides were scored blindly (K.K.) for overall intensity of hepatocellular staining or, alternatively, the numbers of positive macrophages were counted per $40 \times$ field. A: Representative images are shown from each group. Arrows point to macrophages. Insets depict magnifications of the areas with the denoted macrophage(s). B: Quantification results of blinded scoring for hepatocyte and macrophage staining. Data are expressed as means \pm SEM (B). $n=4$ WT mice, with the average counts from three random fields analyzed per mouse (B); $n=5 \mathrm{~K} 0$ mice, with the average counts from three random fields analyzed per mouse $(\mathbf{B}) .{ }^{*} P<0.05$. Original magnification: $\times 400$ (A, main images); $\times 1200$ (A, insets). HFD, high-fat diet; K0, knockout; WT, wild type. 
hepatocytes that was responsible for impaired glucose metabolism, a glucose tolerance test was next performed on mice with a conditional hepatocellular deletion of the HGF receptor, MET, versus their WT counterparts. A discernible difference in glucose metabolism was observed, with a significant difference at 30 minutes after glucose challenge (Figure 5C).

\section{PAI-1 Deficiency Results in Attenuated Macrophage- Mediated Inflammation}

HGF signaling can induce IL-6 production in hepatocytes ${ }^{24}$ or diminish IL-6 production in macrophages. ${ }^{25}$ To determine whether the diet-induced alteration in HGF conversion and subsequent changes in signaling through MET affect cytokine production, two key hepatic proinflammatory cytokines, tumor necrosis factor $-\alpha$ and IL- 6 , were next examined. Significant increases were detected in hepatic protein production of both cytokines in WT animals on an HFD, relative to their PAI-1 KO counterparts, suggesting that the absence of PAI-1 results in an anti-inflammatory environment (Figure 6). Next, livers from animals on an HFD were stained for IL- 6 to determine whether the location of the excess IL-6 in the WT animals could be identified. Although there was a slight trend upward in $\mathrm{KO}$ animals, levels of hepatocellular IL-6 were similar; however, there was a significant increase in positively stained immune cells in the WT animals, relative to the KOs (Figure 7). This was not caused by an increase in macrophage numbers as staining for F4/80 was similar in the two groups (data not shown).

\section{Discussion}

PAI-1, induced in response to chronic inflammation, has long been hypothesized to play a role in exacerbating vascular dysfunction in obesity and subsequent T2D because of its well-established ability in preventing plasmin formation $^{14-16}$; however, there is ample literature to suggest the role of PAI-1 is likely to be more complicated. For example, in the leptin-deficient ob/ob mouse model, disruption of PAI-1 results in reduced adiposity, improved metabolic profiles, and a reduction in the cytokine profile ${ }^{43}$; however, it is the leptin, and not the PAI-1, that is directly related to thrombosis. ${ }^{44,45}$ Hence, the present study sought to determine whether PAI-1-mediated inhibition of HGF activation also plays a role in the development of obesity and T2D.

Because T2D is a polygenic and environmentally/ lifestyle-induced disease, a variation of the classic, dietinduced model of $\mathrm{T} 2 \mathrm{D}^{34}$ was chosen to better ascertain the role of PAI-1 in developing T2D, preferring to use wild-type mice over the monogenic ob/ob diabetes model. Furthermore, a diet $(20 \% \mathrm{kcal}$ of each carbohydrate and protein and $60 \%$ kcal of fat) similar to that previously used by others
(26\% kcal of carbohydrate, $15 \% \mathrm{kcal}$ of protein, and $59 \%$ kcal of fat ${ }^{34,46}$ ), albeit lower in carbohydrates and higher in protein, was used. WT and KO mice, on an HFD or normal chow, were studied over a period of 20 weeks after commencement of diet. As obesity developed, there was a trend toward elevated PAI-1 in the sera of WT animals on the HFD as early as 7.5 weeks after the diet was initiated, with statistical significance reached at 20 weeks after initiation of the diet (Figure 1). Likely, this was because of excess PAI-1 produced by the liver in WT animals as an increase in hepatic PAI-1 was detected at 12 weeks after commencement of the diet using Western blot analyses. Surprisingly, although there was a trend toward a lesser weight gain in the $\mathrm{KO}$ versus WT mice on an HFD, unlike results with a similar study using the original diet ${ }^{46}$ and in the ob/ob mouse model, ${ }^{43}$ the absence of PAI-1 did not have an effect on the increase in weight, possibly because of our earlier implementation of the diet (6 versus 10 weeks $^{43,46}$; ie, it appears that in this model, the development of obesity occurs independently of PAI-1 production). However, similar to the other studies, PAI-1 was found to be an essential regulator of glucose metabolism; the absence of PAI-1 resulted in improved glucose tolerance and insulin resistance (Figures 2 and 3). Thus, this model was suitable for investigating the role of PAI-1 with regard to activation of HGF.

In liver, both u-PA and tissue-type plasminogen activator (t-PA) can facilitate activation of HGF by binding to and then cleaving the latent, single-chain form to the metabolically active two-chain HGF. ${ }^{13}$ As active HGF has been shown to be a positive effector in animal models of diabetes, ${ }^{21,22}$ and can regulate glucose metabolism, ${ }^{23}$ and as the ability of PAI-1 to act as a physiological inhibitor of u-PA activity is well established, ${ }^{47}$ we hypothesized that increased PAI-1 in response to obesity can prevent the activation of HGF and limit its hepatoprotective effects. In $\mathrm{KO}$ animals on an HFD, the conversion of latent HGF to its active form was accelerated, suggesting increased HGF turnover positively regulates glucose metabolism (Figure 4). These data were not unique in this sense since the absence of PAI-1, in the context of specific types of hepatic injuries, is also associated with an increase in active HGF. ${ }^{17,48,49}$ However, as impaired conversion of $\mathrm{HGF}$ in response to overnutrition occurs in the membrane (Figure 4C), it is likely that in the $\mathrm{KO}$ animals, the loss of PAI-1 leads to an increase in MET activation (Figure 5) and a subsequent improvement in the glucose/insulin axis (Figures 2 and 3). In support of this hypothesis, when i.p. glucose tolerance test studies were performed on animals with MET specifically deleted from their hepatocytes, at 30 minutes after injection there was a significant elevation in their glucose levels compared with their WT counterparts (Figure 5C), indicating HGF signaling on the hepatocyte is positively regulating glucose metabolism.

Excessive weight gain or morbid obesity often stimulates chronic inflammation, leading to elevations in circulating cytokines, such as IL-6, as well as acute phase proteins, such 
as PAI-1; these proteins are all known to be produced in the liver by both hepatocytes and macrophages. ${ }^{4,50}$ These results showed that with an HFD, both IL-6 and tumor necrosis factor $-\alpha$ become elevated in livers from WT, but not KO, animals (Figure 6). This indicates that in addition to positively regulating glucose metabolism, the absence of PAI-1 also protected animals on an HFD from developing a chronic inflammatory response. The effects of cytokine suppression were exerted on macrophages (Figure 7). HGF can transiently induce IL- 6 production in hepatocytes, yet suppress the excretion of IL- 6 by macrophages ${ }^{24,25}$; we posit that despite limited IL-6 production in hepatocytes, the HGF may act as a negative regulator of immune cell-mediated cytokine production in these animals. However, it is also possible that the presence of PAI-1 indirectly promotes cytokine production by inhibiting the anti-inflammatory effects of t-PA. ${ }^{51}$ Further studies will be needed to address this.

In conclusion, this study showed that, in WT animals fed an HFD, PAI-1 becomes elevated and prohibits activation of HGF. When PAI-1 is absent, there is an increase in the conversion of latent to active HGF and subsequent signaling through the MET receptor in liver. This increase in MET phosphorylation is associated with overall improved glucose metabolism and increased insulin sensitivity, as well as a decrease in the production of inflammatory cytokines by macrophages.

\section{Acknowledgments}

We thank Snorri Thorgeirsson for providing MET ${ }^{f / f}$ mice.

G.M.C. performed most of the experiments and wrote the manuscript; J.S. helped with lysate preparation, immunoprecipitation, and Western blot analyses; A.V.O. and K.K. performed histologic processing and staining and analyzed the results; S.L. and D.M.P. performed glucose tolerance and insulin resistance testing and harvested tissue; H.H.D. contributed resources and experimental planning with expertise in type 2 diabetes mouse models; B.B. and G.K.M. provided resources and expertise related to the fast food diet and the MET conditional knockout; W.M.M. designed the experiments, devoted expertise in the field of hepatocyte growth factor, plasminogen activator inhibitor type-1, and basic liver pathology, and reviewed/edited the manuscript; J.D.P. designed the experiments and reviewed and edited the manuscript; W.M.M. and J.D.P. are the guarantors of this work and, as such, had full access to all of the data in the study and take responsibility for the integrity of the data and the accuracy of the data analysis.

\section{References}

1. Tataranni PA, Ortega E: A burning question: does an adipokineinduced activation of the immune system mediate the effect of overnutrition on type 2 diabetes? Diabetes 2005, 54:917-927

2. Arkan MC, Hevener AL, Greten FR, Maeda S, Li ZW, Long JM, Wynshaw-Boris A, Poli G, Olefsky J, Karin M: IKK-beta links inflammation to obesity-induced insulin resistance. Nat Med 2005, 11:191-198

3. Cai D, Yuan M, Frantz DF, Melendez PA, Hansen L, Lee J, Shoelson SE: Local and systemic insulin resistance resulting from hepatic activation of IKK-beta and NF-kappaB. Nat Med 2005, 11: 183-190

4. Pickup JC: Inflammation and activated innate immunity in the pathogenesis of type 2 diabetes. Diabetes Care 2004, 27:813-823

5. Pickup JC, Crook MA: Is type II diabetes mellitus a disease of the innate immune system? Diabetologia 1998, 41:1241-1248

6. Weisberg SP, McCann D, Desai M, Rosenbaum M, Leibel RL, Ferrante AW Jr: Obesity is associated with macrophage accumulation in adipose tissue. J Clin Invest 2003, 112:1796-1808

7. Gabay C: Interleukin-6 and chronic inflammation. Arthritis Res Ther 2006, 8 Suppl 2:S3

8. Xing Z, Gauldie J, Cox G, Baumann H, Jordana M, Lei XF, Achong MK: IL-6 is an antiinflammatory cytokine required for controlling local or systemic acute inflammatory responses. J Clin Invest 1998, 101:311-320

9. Liu Y, Michalopoulos GK, Zarnegar R: Structural and functional characterization of the mouse hepatocyte growth factor gene promoter. J Biol Chem 1994, 269:4152-4160

10. Michalopoulos GK, DeFrances MC: Liver regeneration. Science 1997, 276:60-66

11. Zarnegar R, Michalopoulos GK: The many faces of hepatocyte growth factor: from hepatopoiesis to hematopoiesis. J Cell Biol 1995, 129:1177-1180

12. Mars WM, Kim TH, Stolz DB, Liu ML, Michalopoulos GK: Presence of urokinase in serum-free primary rat hepatocyte cultures and its role in activating hepatocyte growth factor. Cancer Res 1996, 56 : 2837-2843

13. Mars WM, Zarnegar R, Michalopoulos GK: Activation of hepatocyte growth factor by the plasminogen activators uPA and tPA. Am J Pathol 1993, 143:949-958

14. Plomgaard P, Keller P, Keller C, Pedersen BK: TNF-alpha, but not IL-6, stimulates plasminogen activator inhibitor-1 expression in human subcutaneous adipose tissue. J Appl Physiol 2005, 98: 2019-2023

15. Samad F, Uysal KT, Wiesbrock SM, Pandey M, Hotamisligil GS, Loskutoff DJ: Tumor necrosis factor alpha is a key component in the obesity-linked elevation of plasminogen activator inhibitor 1. Proc Natl Acad Sci U S A 1999, 96:6902-6907

16. Wind T, Hansen M, Jensen JK, Andreasen PA: The molecular basis for anti-proteolytic and non-proteolytic functions of plasminogen activator inhibitor type-1: roles of the reactive centre loop, the shutter region, the flexible joint region and the small serpin fragment. Biol Chem 2002, 383:21-36

17. Lagoa CE, Vodovotz Y, Stolz DB, Lhuillier F, McCloskey C, Gallo D, Yang R, Ustinova E, Fink MP, Billiar TR, Mars WM: The role of hepatic type 1 plasminogen activator inhibitor (PAI-1) during murine hemorrhagic shock. Hepatology 2005, 42:390-399

18. Mondino A, Blasi F: uPA and uPAR in fibrinolysis, immunity and pathology. Trends Immunol 2004, 25:450-455

19. Lokker NA, Mark MR, Luis EA, Bennett GL, Robbins KA, Baker JB, Godowski PJ: Structure-function analysis of hepatocyte growth factor: identification of variants that lack mitogenic activity yet retain high affinity receptor binding. EMBO J 1992, 11: $2503-2510$

20. Mars WM, Liu ML, Kitson RP, Goldfarb RH, Gabauer MK, Michalopoulos GK: Immediate early detection of urokinase receptor after partial hepatectomy and its implications for initiation of liver regeneration. Hepatology 1995, 21:1695-1701

21. Dai C, Li Y, Yang J, Liu Y: Hepatocyte growth factor preserves beta cell mass and mitigates hyperglycemia in streptozotocin-induced diabetic mice. J Biol Chem 2003, 278:27080-27087

22. Lopez-Talavera JC, Garcia-Ocana A, Sipula I, Takane KK, CozarCastellano I, Stewart AF: Hepatocyte growth factor gene therapy for 
pancreatic islets in diabetes: reducing the minimal islet transplant mass required in a glucocorticoid-free rat model of allogeneic portal vein islet transplantation. Endocrinology 2004, 145:467-474

23. Fafalios A, Ma J, Tan X, Stoops J, Luo J, Defrances MC, Zarnegar R: A hepatocyte growth factor receptor (Met)-insulin receptor hybrid governs hepatic glucose metabolism. Nat Med 2011, 17:1577-1584

24. Norris CA, He M, Kang LI, Ding MQ, Radder JE, Haynes MM, Yang Y, Paranjpe S, Bowen WC, Orr A, Michalopoulos GK, Stolz DB, Mars WM: Synthesis of IL-6 by hepatocytes is a normal response to common hepatic stimuli. PLoS One 2014, 9:e96053

25. Coudriet GM, He J, Trucco M, Mars WM, Piganelli JD: Hepatocyte growth factor modulates interleukin-6 production in bone marrow derived macrophages: implications for inflammatory mediated diseases. PLoS One 2010, 5:e15384

26. Charlton M, Krishnan A, Viker K, Sanderson S, Cazanave S, McConico A, Masuoko H, Gores G: Fast food diet mouse: novel small animal model of NASH with ballooning, progressive fibrosis, and high physiological fidelity to the human condition. Am J Physiol Gastrointest Liver Physiol 2011, 301:G825-G834

27. Kellendonk C, Opherk C, Anlag K, Schutz G, Tronche F: Hepatocytespecific expression of Cre recombinase. Genesis 2000, 26:151-153

28. Committee for the Update of the Guide for the Care and Use of Laboratory AnimalsNational Research Council: Guide for the Care and Use of Laboratory Animals: Eighth Edition. Washington, DC, National Academies Press, 2011

29. Coudriet GM, Delmastro-Greenwood MM, Previte DM, Marre ML, O'Connor EC, Novak EA, Vincent G, Mollen KP, Lee S, Dong HH, Piganelli JD: Treatment with a catalytic superoxide dismutase (SOD) mimetic improves liver steatosis, insulin sensitivity, and inflammation in obesity-induced type 2 diabetes. Antioxidants (Basel) 2017, 6. pii: E85

30. Marre ML, Profozich JL, Coneybeer JT, Geng X, Bertera S, Ford MJ, Trucco M, Piganelli JD: Inherent ER stress in pancreatic islet beta cells causes self-recognition by autoreactive T cells in type 1 diabetes. J Autoimmun 2016, 72:33-46

31. Juhan-Vague I, Alessi MC: PAI-1, obesity, insulin resistance and risk of cardiovascular events. Thromb Haemost 1997, 78:656-660

32. Morange PE, Lijnen HR, Alessi MC, Kopp F, Collen D, JuhanVague I: Influence of PAI-1 on adipose tissue growth and metabolic parameters in a murine model of diet-induced obesity. Arterioscler Thromb Vasc Biol 2000, 20:1150-1154

33. Shimomura I, Funahashi T, Takahashi M, Maeda K, Kotani K, Nakamura T, Yamashita S, Miura M, Fukuda Y, Takemura K, Tokunaga K, Matsuzawa Y: Enhanced expression of PAI-1 in visceral fat: possible contributor to vascular disease in obesity. Nat Med 1996, 2:800-803

34. Surwit RS, Kuhn CM, Cochrane C, McCubbin JA, Feinglos MN: Diet-induced type II diabetes in C57BL/6J mice. Diabetes 1988, 37: 1163-1167

35. Muratsu J, Iwabayashi M, Sanada F, Taniyama Y, Otsu R, Rakugi H, Morishita R: Hepatocyte growth factor prevented high-fat diet-induced obesity and improved insulin resistance in mice. Sci Rep 2017, 7:130

36. Zhang YY, Li C, Yao GF, Du LJ, Liu Y, Zheng XJ, Yan S, Sun JY, Liu Y, Liu MZ, Zhang X, Wei G, Tong W, Chen X, Wu Y, Sun S, Liu S, Ding Q, Yu Y, Yin H, Duan SZ: Deletion of macrophage mineralocorticoid receptor protects hepatic steatosis and insulin resistance through ERalpha/HGF/Met pathway. Diabetes 2017, 66:1535-1547
37. Naldini L, Vigna E, Bardelli A, Follenzi A, Galimi F, Comoglio PM: Biological activation of pro-HGF (hepatocyte growth factor) by urokinase is controlled by a stoichiometric reaction. J Biol Chem 1995, 270:603-611

38. Pedersen AN, Brunner N, Hoyer-Hansen G, Hamer P, Jarosz D, Larsen B, Nielsen HJ, Stephens RW: Determination of the complex between urokinase and its type-1 inhibitor in plasma from healthy donors and breast cancer patients. Clin Chem 1999, 45:1206-1213

39. Miyazawa K, Shimomura T, Kitamura A, Kondo J, Morimoto Y, Kitamura N: Molecular cloning and sequence analysis of the cDNA for a human serine protease responsible for activation of hepatocyte growth factor: structural similarity of the protease precursor to blood coagulation factor XII. J Biol Chem 1993, 268:10024-10028

40. Kataoka H, Shimomura T, Kawaguchi T, Hamasuna R, Itoh H, Kitamura N, Miyazawa K, Koono M: Hepatocyte growth factor activator inhibitor type 1 is a specific cell surface binding protein of hepatocyte growth factor activator (HGFA) and regulates HGFA activity in the pericellular microenvironment. J Biol Chem 2000, 275: 40453-40462

41. Kawaguchi T, Qin L, Shimomura T, Kondo J, Matsumoto K, Denda K, Kitamura N: Purification and cloning of hepatocyte growth factor activator inhibitor type 2, a Kunitz-type serine protease inhibitor. J Biol Chem 1997, 272:27558-27564

42. Qiu D, Owen K, Gray K, Bass R, Ellis V: Roles and regulation of membrane-associated serine proteases. Biochem Soc Trans 2007, 35: $583-587$

43. Schafer K, Fujisawa K, Konstantinides S, Loskutoff DJ: Disruption of the plasminogen activator inhibitor 1 gene reduces the adiposity and improves the metabolic profile of genetically obese and diabetic ob/ob mice. FASEB J 2001, 15:1840-1842

44. Konstantinides S, Schafer K, Loskutoff DJ: The prothrombotic effects of leptin possible implications for the risk of cardiovascular disease in obesity. Ann N Y Acad Sci 2001, 947:134-141. discussion $141-142$

45. Konstantinides S, Schafer K, Neels JG, Dellas C, Loskutoff DJ: Inhibition of endogenous leptin protects mice from arterial and venous thrombosis. Arterioscler Thromb Vasc Biol 2004, 24:2196-2201

46. Ma LJ, Mao SL, Taylor KL, Kanjanabuch T, Guan Y, Zhang Y, Brown NJ, Swift LL, McGuinness OP, Wasserman DH, Vaughan DE, Fogo AB: Prevention of obesity and insulin resistance in mice lacking plasminogen activator inhibitor 1. Diabetes 2004, 53:336-346

47. Cubellis MV, Andreasen P, Ragno P, Mayer M, Dano K, Blasi F: Accessibility of receptor-bound urokinase to type-1 plasminogen activator inhibitor. Proc Natl Acad Sci U S A 1989, 86:4828-4832

48. Arteel GE: New role of plasminogen activator inhibitor-1 in alcoholinduced liver injury. J Gastroenterol Hepatol 2008, 23 Suppl 1: S54-S59

49. Wang H, Zhang Y, Heuckeroth RO: PAI-1 deficiency reduces liver fibrosis after bile duct ligation in mice through activation of tPA. FEBS Lett 2007, 581:3098-3104

50. Wellen KE, Hotamisligil GS: Inflammation, stress, and diabetes. J Clin Invest 2005, 115:1111-1119

51. Mantuano E, Azmoon P, Brifault C, Banki MA, Gilder AS, Campana WM, Gonias SL: Tissue-type plasminogen activator regulates macrophage activation and innate immunity. Blood 2017, 130: 1364-1374 